\title{
The Role of Service Providers, Technology, and Mass Media When Home Isn't Safe for Intimate Partner Violence Victims: Best Practices and Recommendations in the Era of COVID-19 and Beyond
}

\author{
Danielle C. Slakoff ${ }^{1}\left[\right.$. Wendy Aujla ${ }^{2}$ (I) $\cdot$ Eva PenzeyMoog ${ }^{3}$
}

Received: 9 July 2020 / Revised: 5 August 2020 / Accepted: 8 August 2020 / Published online: 25 August 2020

(c) Springer Science+Business Media, LLC, part of Springer Nature 2020

\section{Introduction}

COVID-19, also known as the novel coronavirus, has led to worldwide uncertainty. Millions of people around the world have lost their jobs (Cave, 2020; Partington, 2020), and some medical health professionals in COVID-19 "hotspots" are experiencing depression and anxiety due to extreme workload (Gold, 2020). Within this context, another pressing issue has come to the fore: domestic violence (DV) and intimate partner violence (IPV) victims and survivors are being asked to shelter in place with their abusers. ${ }^{1,2}$ Extant research indicates that disaster situations tend to place IPV victims at greater risk (Buttell \& Carney, 2009; Lauve-Moon \& Ferreira, 2017). While both men and women face IPV, statistics indicate women are at higher risk and more likely to be killed by male perpetrators. In Canada, a woman or girl is killed every 2.5 days, on average, usually by a current or former male partner (Dawson, Sutton, Carrigan, \& Grand'Maison, 2018). Thus, this Commentary is written with female victims in mind.

To protect themselves during non-disaster circumstances, IPV victims may seek help from informal (friends, family, neighbors, etc.) and formal supports, such as courts, police, shelters, and social service providers (see also Aujla, 2020). In this Commentary, we define social service providers as organizations that help victims secure safe shelter or housing, review safety plans, facilitate peer support groups and mental

Danielle C. Slakoff

danielle.slakoff@csus.edu

1 Division of Criminal Justice, California State University, Sacramento 6000 J Street, Sacramento, CA 95819, USA

2 Department of Sociology, University of Alberta, Edmonton, $\mathrm{AB}$, Canada

3 The Inclusive Safety Project, Chicago, IL, USA health counseling, and more (Aujla, 2010). In addition to this work, social service providers are now also responsible for limiting the spread of COVID-19 in their facilities, which may prevent them from operating at full capacity (Taub, 2020). Shelters were already struggling to meet demand before COVID-19 (The Canadian Press, 2020), and given that the most dangerous time for a victim is when they leave the relationship (National Coalition Against Domestic Violence, 2020), the lack of emergency shelter space may put victims at an even greater risk.

In this Commentary, we describe best practices for social service providers during and after the COVID-19 pandemic, and we offer recommendations to service providers, shelter workers, and technologists (e.g., designers, developers, project managers) working to make the world safer for DV victims. As the pandemic continues to constrain women's access to informal and formal supports, we also highlight the media's role in educating the public about IPV.

\section{The Current Climate: The Media's Portrayal of COVID-19 and Domestic Violence}

In order to frame our discussion of how COVID-19 is impacting DV, we reviewed key themes in early newspaper coverage of the pandemic. Specifically, we looked at

\footnotetext{
${ }^{1}$ DV refers to violence within a home, including child abuse, elder abuse, and IPV; IPV is defined by the World Health Organization (WHO) as "physical, sexual, and emotional abuse and controlling behaviours by an intimate partner" (2012, p. 1; see also Stark, 2007). Given that IPV falls under the umbrella of domestic violence, we use both terms throughout this Commentary.

2 The Rape, Abuse \& Incest National Network (2020) uses the term "'survivor' to refer to someone who has gone through the recovery process" (para. 3). We use the term victim to refer to a woman who is being or has recently been victimized by a current or former partner (perpetrator).
} 
eight nationally distributed news stories from papers in four countries (the U.S., Canada, the United Kingdom, and Australia). ${ }^{3}$ All four countries have similar victim safety services available; however, each country has a different definition of family violence, and the differences are beyond the scope of this Commentary. Moreover, though the newspapers were based in those four countries, they included information about other countries affected by the pandemic. Like Foster and Fletcher (2020), we note that it is far too early to understand the full impact of COVID-19 on women's access to support services. However, across the news articles about COVID-19 and DV, some clear themes emerged.

The most prominent themes across articles were that reports of DV increased, and calls to DV support services spiked in various locales. Increased helpline calls should not be conflated with increased prevalence of abuse; however, these themes speak to the pressure placed on social service providers in the COVID-19 era. ${ }^{4}$ In a New York Times article, Selvaratnam (2020) wrote that "reports of domestic violence have nearly doubled since cities went into lockdown" and mandated physical distancing in China (para. 2). In the Sydney Morning Herald (Australia), Thompson (2020) wrote that "front-line family violence workers report[ed] a sharp increase in violence after the first week of stringent lockdown measures" (para. 8; see also Rawsthorne, 2020). With regard to calls for service, in The Guardian (United Kingdom), Townsend (2020) explained that "the UK's largest domestic abuse charity, Refuge, [had] reported a $700 \%$ increase in calls to its helpline in a single day" (para. 3). Similarly, the Toronto Star (Canada) reported that "that the Battered Women's Support Society of Vancouver [had] reported a 300 per cent increase in daily calls in recent weeks" (The Canadian Press, 2020, para. 2).

Pandemic-related isolation from support networks and jobs can give abusers unlimited access to victims (Rankin, 2020; Rawsthorne, 2020) and fewer "eyes on families" that may protect victims (The Canadian Press, 2020, para. 3). In the New York Times, Taub (2020) described how "shattered support networks [make] it far more difficult for victims to get help or escape" (para. 25) and abusers gain more power

\footnotetext{
3 We used Google to conduct four searches on April 18, 2020: "New York Times COVID-19 domestic violence," "The Toronto Star COVID19 domestic violence," "The Sydney Morning Herald COVID-19 domestic violence," and "The Guardian COVID-19 domestic violence." We read the first two newspaper articles (not videos) of each search. Note: That same day, a man killed 22 people in Nova Scotia after first attacking his long-term partner (Lamoureux, 2020). While the shooting did not affect our selected stories, it may be part of future articles written about DV and COVID-19.

${ }^{4}$ New publications confirm that frontline services are responding to an increase in clients seeking help (see Foster \& Fletcher, 2020; Pfitzner, Fitz-Gibbon \& True, 2020). For example, Pfitzner et al. (2020) surveyed 166 practitioners in Australia and found that the pandemic has increased the number of DV cases and service use.
}

over victims in quarantine conditions. The articles described how, in response to the dismantling of in-person support networks, social service providers launched large-scale efforts to offer victims services via phone, online, and/or virtual chat sessions (Grierson, 2020; Rankin, 2020; Selvaratnam, 2020; The Canadian Press, 2020). Some articles linked to lists of services (Taub, 2020) or included service provider telephone numbers and websites (Townsend, 2020).

While technological and electronic resources are recommended, the complexity of safely offering online services is a major concern. The Director of Toronto's Barbara Schlifer Commemorative Clinic told the Toronto Star, "The situation is grim for a lot of people and for us as well. This is a completely new world order, to actually make yourself and your services available in a safe way for the workers... while also making sure that the clients are getting the service" (Rankin, 2020, para. 19). It is not always safe to receive services when an abuser is nearby (Rankin, 2020). The themes found in early newspaper reporting about the pandemic and DV contextualize and clarify key issues surrounding victims' safety during the COVID-19 era.

\section{Theoretical Context}

\section{Intimate Partner Violence and Disaster: An Overview}

The literature about Intimate Partner Violence during and after disasters is not an exact parallel with the COVID-19 pandemic, since many disasters lead to a wholesale loss of services whereas the pandemic has not. However, the IPV and disaster literature illuminate some key challenges in the COVID-19 era. Importantly, several studies have shown a marked increase in IPV rates in the aftermath of disasters (Buttell \& Carney, 2009; Lauve-Moon \& Ferreira, 2017). Disasters often place a large strain on social service providers, which may experience much higher call volumes (Rao, 2020) or a marked increase in women and children seeking shelter through anti-violence coalitions (Enarson, 1999).

Many disasters can disrupt or prevent victims from accessing important social supports, such as their families (Jenkins \& Phillips, 2008; Lauve-Moon \& Ferreira, 2017) or social service providers (Baker \& Cormier, 2015; Sety, 2012). During the COVID-19 crisis, physical distancing mandates and stay-at-home orders may exacerbate this loss of access. After disasters, social service providers may feel overwhelmed with a sudden uptick in demand for services (Sety, 2012); in the COVID-19 era, social service providers may also fall ill or need to quarantine. Moreover, the sudden transition to offering services remotely due to COVID-19 has presented challenges and increased stressors for service providers (Foster \& Fletcher, 2020; Pfitzner et al., 2020). 
During natural disasters, actual infrastructure may be destroyed (Jenkins \& Phillips, 2008). While COVID-19 has not damaged buildings, shelters and social service locations may have closed, reduced face-to-face hours, or limited their capacities due to physical distancing mandates. Importantly, "services for violence prevention and intervention were already struggling to meet needs before the arrival of COVID-19" (Gunraj \& Howard, 2020, para. 10). In the COVID-19 era, some shelters have used social media to ask for financial support and increase awareness of DV. Some service providers have argued for additional government support to help fund their operations during COVID-19 (Foster \& Fletcher, 2020; Pfitzner et al., 2020).

A decrease in the availability of support services during or after a disaster (as detailed by Baker \& Cormier, 2015) can have negative long-term impacts on victims. Indeed, support services help victims in their healing and empowerment process (Lum, 1996). Moreover, research shows an IPV victim's psychological recovery in the context of a disaster can take longer than their recovery when disaster is not involved (Buttell \& Carney, 2009), likely due to compounding issues with housing scarcity (Sety, 2012) and unemployment (Lowe, Rhodes, \& Scoglio, 2012). Simply put, access to support services is always important for IPV victims, but the need is heightened during and after disasters.

\section{Coercive Control}

Understanding what coercive control looks like-particularly within the COVID-19 context — will impact early interventions and could help reduce harm. Stark (2007) defined "coercive control" as a (usually male) perpetrator's abusive pattern of behavior-including violence, intimidation, threats, isolation, and controlling tactics - that has negative long-term impacts on victims (usually women) (p. 228; see also Hamberger, Larsen \& Lehrner, 2017; Terrazas-Carrillo, McWhirter \& Martel, 2016). Coercive control often involves surveillance, stalking, and the gendered "microregulation of everyday behaviors" associated with housework and childcare (for more examples, see Stark, 2007, p. 5; see also Hamberger et al., 2017).

Importantly, abusers may intensify coercion and control during the COVID-19 pandemic, including minimizing or monitoring victims' communication with friends and family; depriving victims of their basic needs; withholding information about the virus and public health measures; and restricting access to the Internet, medications, and personal hygiene products such as masks, gloves, cleaning supplies, hand soap, and sanitizer (The Learning Network at the Centre for Research \& Education on Violence Against Women \& Children in Canada, 2020; Safe \& Together Institute, 2020).
Coercive Control and Technology-Related Domestic Violence

Technology may help victims maintain access to informal and formal supports. However, abusers also use technology to facilitate coercive control; most IPV survivors say they have experienced technological surveillance, such as having spyware software installed on their devices by their abusers (George \& Harris, 2014; Greenberg, 2019). Practitioners in Australia have noted that abusers reduce victims' abilities to seek help by limiting access to mobile phones and computers during the pandemic: "Women have been very concerned about their phone calls being overheard and not having a safe space to speak freely. Women have often ended phone calls, changed the topic or called back later when it is safe to talk" (Pfitzner et al., 2020, p. 12). When creating and implementing safe tech-based spaces for victims in the era of COVID-19 and beyond, social service providers and technologists must consider the realities of technology-based coercive control (Dragiewicz et al., 2018).

\section{Best Practices and Recommendations}

In this section, we discuss current best practices and provide recommendations for three groups playing key roles in supporting IPV victims during the COVID-19 crisis: social service providers, technologists, and media personnel.

\section{Best Practices for Social Service Providers}

Service providers have responded to the pandemic as best they can give the resources available. In what follows, we discuss recommendations for best practices and future research in four key areas: (1) protocol development; (2) coercive control and intersectionality; (3) prevention and intervention; and (4) education for informal supports. These approaches can be beneficial both during and after the pandemic.

\section{The Development of Domestic Violence Protocols}

Service providers should continue to update written guidelines (e.g., DV protocols) for staff to help facilitate clear and consistent victim support during the COVID-19 era. Some organizations in the DV sector are developing standardized protocols, so staff feels better prepared to work with IPV victims during this uncertain time. IMPACT, a network of service providers across Alberta, Canada, provides training and resources for supporting DV victims during the pandemic (Sagesse, 2020). Importantly, IMPACT is also working on 
creating protocol documents for marginalized communities. ${ }^{5}$ These protocols are working documents that offer practical recommendations to communicate vital information with clients (e.g., remote working hours, the types of support available online and by phone). For example, shortly after the start of the COVID-19 outbreak, the Alberta Council of Women's Shelters (2020a) developed interim guidelines for shelter service providers that explained how to provide support and safe accommodations to victims while adhering to public health recommendations.

Given the pandemic's unpredictable nature, documents and resources should be shared widely with service providers across the DV sector. While we recognize this task is difficult in the best of times, in response to COVID-19, organizations like Sagesse (2020) have published standardized protocols on their websites to facilitate communication between providers. These standardized protocols should outline multi-agency collaboration and coordination of services and are worth the effort to create because they can help mitigate the burnout and financial challenges faced by providers with fewer staff and resources.

\section{Coercive Control and Intersectionality}

In both "normal" and pandemic times, service providers should consider Stark's (2007) concept of coercive control to broaden agency definitions of IPV beyond physical violence. For example, the United Kingdom's Home Office (2015) redefined DV to include coercive control, and the law now criminalizes such behaviors. To be clear, we are not suggesting that service providers shift their paradigms to accommodate coercive control in the middle of a global or even national emergency. Instead, we recognize that prior to COVID-19, some organizations were already trying to redefine DV and revise their approaches to account for coercive, controlling behaviors. For example, Sagesse (2020) has responded to the pandemic by delivering workshops on DV and coercive control.

Furthermore, service providers should always consider how a person's multiple identities shape their experiences with IPV. By examining IPV through an intersectional lens (Crenshaw, 1991), service providers will be better able to tailor support for victims with multiple marginalized identities. For example, impoverished victims may lack access to phone or Internet service, and both are key access points for remote help (as described in Foster \& Fletcher, 2020). Service providers must prioritize finding ways to give victims access to phone or Internet services before they can provide help.

\footnotetext{
5 The second author of this commentary has been invited to review protocols developed by Sagesse and partner organizations for working with ethnocultural communities.
}

\section{Prevention and Intervention}

Service providers should educate victims on COVID-19, so they can recognize if their abuser is using misinformation about the virus to maintain control over them (WHO, 2020). Moreover, service providers should continue to offer crisis and counseling support via the Internet, telephone, and text messaging, with an understanding that different victims experience IPV differently (Lippy, Jumarali, Nnawulezi, Williams, \& Burk, 2020). Being isolated with an abuser during the pandemic further limits a victim's access to informal and formal supports (Taub, 2020; Townsend, 2020). While there are safe, free, and confidential 24-h Family Violence Helplines in multiple languages, the victim may be unable to access them due to the perpetrator's increased power and control.

In some ethnocultural communities, there can be multiple perpetrators such as a partner, mother-in-law, and sister-inlaw-this dynamic can lead to challenges in reporting abuse and accessing supports (see Aujla, 2020). Each support session should be tailored to the client's individual needs. A lack of cultural sensitivity may lead to a victim feeling alienated by the system and uncomfortable seeking help via formal services and supports (Aujla, 2020).

Service providers play a crucial role, as formal supports, in recognizing safety concerns and supporting victims who reach out, including assessing risks and creating a safety plan to support victims in isolation. Standard aspects of a safety plan include who to contact for help if abuse escalates, the safest rooms in the home, and which personal items should be placed together in case of a swift exit (Alberta Ministry of Justice and Solicitor General, 2019). The COVID-19 era introduces new barriers to safety planning, as it can be difficult to conduct risk assessments when the victim is at home with their abuser(s) or may be overheard (Pfitzner et al., 2020). In response to pandemic-related physical distancing measures, safety plans should also include how to safely use technology and which organizations' websites have a quickescape feature. Service providers can ask victims to establish code words or "signals of distress" with family, friends, and/ or neighbors (Canadian Women's Foundation, 2020). The safety plan should also be culturally sensitive (Rossiter et al., 2018); immigrant women may experience difficulty accessing services, and this difficulty may be compounded by the stresses of the pandemic. As Aujla (2010) argued, "having more information about what is offered at each shelter can assist a woman in planning her own escape, and it can further allow others to become more knowledgeable of services so that they may also make referrals" (p. 72).

Social service providers must also consider technologyfacilitated abuse, as an abuser may surveil, monitor, or hack the victim's telephone or computer without the victim's knowledge. This type of abuse is particularly challenging 
during the pandemic, since so much communication has moved online. Once contact with a victim has been established, staff must quickly and effectively build a social support network and safety plan. Service providers may only have one chance to speak privately with victims (Pfitzner et al., 2020), as their abusers may discover the communication and prohibit further contact.

Another primary concern is how to quickly address the shortage of shelter space. As described by Taub (2020), Townsend (2020), and Thompson (2020) in early media reporting about COVID-19 and IPV, in several countries vacant hotel rooms have turned into emergency shelter space. However, this option is costly, and few service providers can afford it without government assistance (Townsend, 2020). In the COVID-19 era, it is important to update protocols so that victims can safely check in and maintain cleanliness to prevent the virus's spread. For example, shelters in Saskatoon, Saskatchewan, are placing victims tested for COVID-19 in hotel rooms instead of shelters (Eneas, 2020).

\section{Education for Informal Supports}

Given that victims tend to disclose IPV to informal supports first (Aujla, 2020; Barrett \& Pierre, 2011), service providers should educate all people to recognize and respond to IPV, and to know when and how to refer victims to formal supports. Specifically, informal supports need to know that formal services (e.g., women's shelters) are still available during the pandemic, but under different circumstances, such as remote work or limited capacity. DV organizations should share updated information on who to contact, hours of operation, and other important details so referrals can be made in a timely manner.

Service providers such as Sagesse and Calgary Women's Emergency Shelter Programs and Services are already offering online training on DV responses within the COVID-19 context. The webinars have included explanations of coercive controlling behaviors and how to facilitate supportive conversations with IPV victims/survivors. Like Sagesse (2020), other service providers should—if possible—offer virtual training sessions to help informal supports recognize or establish clues or alerts from an individual who needs help, such as flickering outdoor lights, opening or closing blinds, or waving from certain windows. A victim may also signal for help during a video call by using a tucked-thumb and closed-fist hand gesture (Canadian Women's Foundation, 2020; Pfitzner et al., 2020). In their public awareness toolkit, the Alberta Council of Women's Shelters (2020b) suggested using code words such as "we are out of milk" to tell informal supports that the victim needs help.

\section{Practical Recommendations for Technologists}

Given service providers' reliance on phone- and Internetbased services during the COVID-19 era, an important next step is helping technologists to create safe online spaces for IPV victims. A technologist is anyone who works in the tech field and influences the way digital products are designed and built. They can aid DV victims and advocates in several ways.

\section{Technology Education for Advocates and Victims}

Technologists should partner with DV organizations to ensure that advocates and victims have the most up-to-date information on methods that abusers use to monitor and track their victims via digital tools (see VAWNet, 2020b, for a technology-based DV resource list for service providers), and they should create educational resources to help victims stay safe online. For example, technologists could host educational webinars for victims and advocates to learn about technological advances in this space, or they could help create digital toolkits for people looking to learn more about IPV and safe online communication during COVID-19 (for an example of a digital toolkit, see National Network to End Domestic Violence, 2020).

Technology education for victims and advocates should include an overview of these safety-oriented applications and tools:

1. Incognito mode, a setting that prevents browser history from being stored and prevents web pages, images, and cookies from being saved to the user's computer.

2. The Circle of 6 app, which allows a victim to use two taps to seek help from a select group of people by sending a pre-programmed text message with their location. The app can also send a text asking someone to call the user at a moment that needs to be interrupted.

3. The One Love app, which has a danger checklist and validates that, "Yes, this is abuse," to those who might not be sure. This app is useful for victims/survivors and concerned friends and family.

4. Within-game chat features, which a victim could use instead of texting to get assistance and make a safety plan with friends or family. Some abusers may check text messages but may not check the chat feature in a game.

5. Digital communication products that do not require an app to be downloaded to the survivor's device, such as Gruveo, an encrypted web-based video chat service used by some organizations in Victoria, Australia to connect with victims who are isolating at home during COVID19 (Pfitzner et al., 2020). 


\section{Novel Digital Aid Tools}

There are several projects technologists could take on to aid DV victims experiencing violence while sheltering at home. These initiatives would be especially useful while traditional informal and formal support networks are reduced or unavailable and would remain beneficial after the crisis is over. One such project is to create a "shielded website" tool modeled after that of New Zealand's Women's Refuge (2016). A shielded website has a specific icon in the footer that, when clicked, launches a modal window (similar to a pop-up, a modal window presents new information without leaving the current page) with information about DV, a "live chat" option, available support options, safety planning, and a contact form to receive a call or email from a support professional. The tool is intended to be used on non-DV-related websites, such as business or university sites. Using a modal window means that only the host website will show up in the browser history, making it a safe and secure method for accessing support for victims whose abusers are monitoring their Internet usage. These tools are country-specific, and technologists around the world should consider partnering with DV organizations to create a tool for websites in their countries.

Other promising technologies to aid survivors might inspire technologists either to create similar products for their local support systems or to consider other ways to help survivors. First, a digital tool—such as an online court document filing system-could facilitate legal processes that are normally conducted in-person or by phone. Such an app is already in use in Yolo County, California, and was created by a UC Davis School of Law student (Meyer, 2020). Second, technologists might consider creating platforms that assess the user's safety and provide local resources; for example, the Distance Domestic Violence tool was created by a student at the Massachusetts Institute of Technology in response to COVID-19 (Fulara, 2020). Third, product creators might consider how to modify existing features (or create new ones) to help survivors. For example, Snapchat, a popular multimedia messaging app, will soon offer resources for victims/ survivors and those who want to support them (Fried, 2020). Notably, the resources will include subtitles, allowing people to view the content silently and safely. This feature is a great example of user-focused design, since Snapchat considered the potential danger to survivors trying to access support.

\section{Quick-Escape Buttons}

Given that abusers may monitor victims' online activities (Douglas, Harris, \& Dragiewicz 2019; Dragiewicz et al., 2018), websites with content that may put survivors at risk should use a "quick-escape" button, which allows the user to quickly exit a site. These buttons are commonly used on the websites of DV and abortion service providers for safety reasons: The user may need to quickly close the site if someone enters the room. Quick-escape buttons are large and often have a high contrast to the surrounding content, making them quicker to locate than the small " $x$ " that closes a tab. They are also more discreet than closing a laptop or turning off a monitor.

Technologist Gu (2019) designed a quick-escape feature for the Midwest Access Coalition, which helps people access safe, legal abortions. Gu's recommendations for designing quick-escape buttons include ensuring that the button is able to be used anywhere on the site, at any time. Quick-escape buttons should also be "sticky," meaning they stay in place as the user scrolls. Technologists should consider additional functionality; clicking the button could both close the current website and launch a new one that appears innocent and is unlikely to raise an abuser's suspicions, such as a Google Images search for a specific animal. Also, clicking the "back" button on the new site should take the user to the site they visited before the site with the quick-escape button. This design recommendation is against general best practices for user experience, but the user's increased safety is worth it.

\section{Inclusive Safety Design}

Like Suzor et al. (2019), we believe companies must take proactive steps toward combating technology-facilitated abuse. Technologists should use PenzeyMoog's (2020) Framework for Inclusive Safety to consider the ways their products can be subverted for domestic violence and other misuse (see also PenzeyMoog \& Slakoff, in press). The five steps recommended are: (1) include a DV research lens; (2) create DV personas; (3); design for DV personas; (4) identity areas where user behavior might indicate abuse and consider how the product might offer support; (5) include usability test scenarios of abuse (DV and stress testing).

Advocates and those in the DV sector could also help technologists understand the perpetrator mindset and digital coercive control, which will help technologists design safer websites and apps. Moreover, with the help of social service providers, technologists can create tools that are accessible to people of various backgrounds (a need described in Aujla, 2010).

\section{How the Media Can Help}

According to agenda-setting theorists, the media affects what issues people think about and how they feel about them (McCombs \& Shaw, 1972). As Berns (2009) claimed, "most people use the media to learn about social problems" (p. 7). The media play a key role in educating the public about IPV (Gillespie, Richards, Givens, \& Smith, 2013) because the 
framing of IPV can influence viewers' perceptions of abusers and victims (Berns, 2009). Given that media personnel are in the unique position of being able to quickly disseminate information to large swaths of society (Surette, 2007), we argue the media should take the opportunity to educate readers and viewers about IPV (as described in Special Taskforce on Domestic and Family Violence, 2015). As Berns (2009) stated:

It is time to pay attention to why people use violence and other abusive strategies, what can be done to help them, and how we can prevent others from abusing their partners and families. We have research and social programs that address these questions, but we have seen little of this knowledge get transferred through the media to the public. (p. 165)

In their examination of newspaper articles about fatal DV, Gillespie et al. (2013) found $12 \%$ of articles contextualized the murder by describing DV as a broader social problem. In early media coverage of the pandemic, newspaper stories framed the intersection of COVID-19 and DV as a worldwide, pressing issue, which is a positive step forward. However, journalists should take care to describe the issues facing social service providers all the time, not just in times of crisis. Additionally, when describing DV during the pandemic, the media should not mistakenly imply that COVID19 is the cause of abuse as this misinforms the public. To be clear, abusers' controlling behaviors may be exacerbated by COVID-19, but the virus itself does not cause violence. As described by Mithani (2020), "domestic violence is about power and control, and when your job, finances and livelihood are all up in the air, abuse becomes a place where people seek to regain that sense of control" (para. 5). Media personnel should explain this distinction, and this framing may shift how the general public responds to IPV during the COVID-19 era. The media could also educate the public on DV and abusive strategies prior to COVID-19, coercive control and technology-facilitated DV, prevention and intervention programs for $\mathrm{DV}$, and how informal supports can help DV victims feel safe while at home.

Richards, Gillespie, and Smith (2011) found newspaper stories that framed DV as a broad social issue tended to include advocates' voices. During the pandemic and in the future, journalists should continue to offer a platform to social service providers. With this platform, these advocates can educate the public - including victims and informal supports-about IPV and help-seeking strategies and also ask for financial or logistical support. Some scholars have argued against the use of individualized narratives in stories about IPV because they might insinuate that IPV is not a prevalent social issue (Fairbairn \& Dawson, 2013). However, in order to humanize the issue of IPV during COVID-19, the media could describe IPV as a broad social problem and include victim/survivor perspectives to help the public understand the complexity of IPV and the challenges of accessing resources.

Finally, the media is a powerful institution that can place political pressure on government officials and force public accountability (Unger, 2018). Indeed, in the U.S., policymakers turn to news reports to decide which issues warrant a political response (Yanovitzky, 2002). With a media focus on IPV, policymakers may feel compelled to act (Ryan, Anastario, \& DaChunha, 2006). With this in mind, the media should challenge government officials to invest in the critical infrastructure and financial support that social service providers desperately need, both in "normal" times and in times of emergency.

\section{Discussion}

COVID-19, like other disasters, creates additional challenges for organizations that support victims of IPV, such as issues relating to physical distancing measures, isolation, and communication difficulties between victims and support networks. During times of great turmoil, DV sector organizations must creatively consider how to keep victims safe, often depending on the help of informal supports and discrete technologies. Technologists must consider coercive control when creating technology designed to help victims, and media personnel must carefully frame the problem to help educate the general public and informal supports about the realities of IPV.

Although many DV sector organizations have remained open during the pandemic, many of them have also made their services available online or by phone in case a victim cannot leave their home or feels unsafe doing so (DC Coalition Against Domestic Violence, 2020; Refuge, 2020; Pfitzner et al. 2020). The impact of this large-scale move toward technology-based services, while absolutely necessary given physical distancing orders, will not be fully understood for some time. However, the importance of a symbiotic relationship between service providers and technology has never been more apparent, and a well-coordinated DV disaster-response protocol must include technology. As technology advances, service providers must continue refining their emergency protocols.

\section{Directions for Future Research}

Service providers on the COVID-19 frontlines are working as hard as they can with the tools available to them. As we move forward, it is important to understand how COVID19 has affected their work. Researchers should build upon the work done by Women's Safety NSW (Foster \& Fletcher, 2020) and Monash University's Gender and Family Violence Prevention Centre (Pfitzner et al., 2020) on Australian service 
providers' experiences, challenges, and adaptations during the COVID-19 outbreak.

Another important avenue of research includes examining service providers' experiences with vicarious trauma, compassion fatigue, work-related post-traumatic stress disorder, and burnout during the pandemic (see Lipsky \& Burk, 2009 , for information on how to respond to trauma exposure). Service providers on the frontlines are facing enormous pressures to provide compassionate and empathic care for victims despite the ways COVID-19 has increased their workload, and this new reality seems likely to continue for some time. As the DV sector adapts, we must not dismiss the impact of COVID-19 on service providers' health and well-being. ${ }^{6}$ Researchers should examine technologists' perceptions of the effects of COVID-19 on online safety (in the DV sector and beyond), as well as media personnel's experiences reporting on DV and COVID-19. It is possible that media personnel receive no formal training on the complexity of DV, which may affect their reporting.

Researchers should also seek to understand women's help-seeking experiences during and after the COVID-19 era. We know women's experiences with IPV differ based on intersecting identities such as age, gender, motherhood status, immigration status, class, race, and ethnicity (Lippy et al., 2020), and researchers must consider how these identities impacted victims' access to help. For example, in some ethnocultural multi-generational households, victims may be unable to seek support during the pandemic, even online. Moreover, women from ethnocultural communities may experience cultural and language barriers when trying to access support during non-pandemic times (Aujla, 2020; Rossiter et al., 2018); during this crisis, those barriers may be larger. A deeper understanding of women's diverse helpseeking experiences during and after COVID-19 will help inform effective emergency protocols for future disasters.

\section{Conclusion}

Even during the best of times, DV and shelter service providers are over-worked and under-resourced (Iyenger \& Sabik, 2009), and the COVID-19 pandemic has exacerbated many ongoing issues across all helping fields. This moment of great international strife clarifies the need for DV sector organizations to proactively create emergency contingency plans. However, efforts to increase service effectiveness are difficult without financial and logistical support. Federal governments face a moral imperative to help fund DV service providers before, during, and after disaster situations. In response to COVID-19, Canada's government announced $\$ 40$ million

\footnotetext{
${ }_{6}$ VAWNet (2020a) recently publicized a webinar for advocates on self-care and combating compassion fatigue.
}

in funding for women's shelters (including $\$ 10$ million for Indigenous women and children accessing shelters) and sexual assault centers across the country. Similarly, the Australian government has committed to providing additional funding for safe accommodations and technology supports (Pfitzner et al., 2020). We hope to see these funding programs continue after the COVID-19 crisis fades from the headlines and hope citizens will hold elected leaders accountable if they fail to do so.

\section{References}

Alberta Council of Women's Shelters. (2020a). Domestic violence and COVID 19. Retrieved May 20, 2020 from https://acws.ca/wp-conte nt/uploads/2020/04/2020-03-27_COVID19-InterimGuidelinesDV. pdf.

Alberta Council of Women's Shelters. (2020b). How you can respond to DV during COVID-19. Retrieved May 20, 2020 from https://acws. ca/wp-content/uploads/2020/04/2020-04-08_How-you-can-respo nd-to-DV-DURING-COVID.pdf.

Alberta Ministry of Justice and Solicitor General. (2019). Strategies for safety. Retrieved May 17, 2020 from https://open.alberta.ca/ dataset/79189049-0cfe-484d-9db9-b23a654a46bf/resource/5d86a 959-ef81-4b97-9e3a-f9a2f8349a68/download/strategies-for-safet y.pdf.

Aujla, W. (2010). Domestic violence and immigrant women's access to services in Edmonton, Alberta. Annual Review of Interdisciplinary Justice Research, 1, 58-76.

Aujla, W. (2020). "It was like sugar-coated words": Revictimization when South Asian immigrant women disclose domestic violence. Affilia: Journal of Women and Social Work. https://doi. org/10.1177/0886109920916038.

Baker, L. R., \& Cormier, L. A. (2015). Disasters and vulnerable populations: Evidence-based practice for the helping professions. New York: Springer Publishing Company.

Barrett, B. J., \& Pierre, M. S. (2011). Variations in women's help seeking in response to intimate partner violence: Findings from a Canadian population-based study. Violence Against Women, 17(1), 47-79.

Berns, N. (2009). Framing the victim: Domestic violence media and social problems. Piscataway, NJ: Transaction Publishers.

Buttell, F. P., \& Carney, M. M. (2009). Examining the impact of Hurricane Katrina on police responses to domestic violence. Traumatology, 15, 6-9.

Canadian Women's Foundation. (2020). Signal for help. Retrieved May 18, 2020 from https://canadianwomen.org/signal-for-help/.

Cave, D. (2020). A lucky country says goodbye to the world's longest boom. The New York Times. Retrieved May 20, 2020 from https ://www.nytimes.com/2020/03/27/world/australia/australia-coron avirus-economy.html.

Crenshaw, K. (1991). Mapping the margins: Intersectionality, identity politics, and violence against women of color. Stanford Law Review, 43(6), 1241-1299.

Dawson, M., Sutton, D., Carrigan, M., \& Grand'Maison, V. (2018). \#Callitfemicide: Understanding gender-related killings of women and girls in Canada, 2018. Canadian Femicide Observatory for Justice and Accountability. Retrieved May 22, 2020 from https:// femicideincanada.ca/callitfemicide.pdf.

DC Coalition Against Domestic Violence. (2020). Coronavirus (COVID-19) resources for survivors. Retrieved May 19, 2020 from https://dccadv.org/2020/03/coronavirus-covid-19-response/. 
Douglas, H., Harris, B. A., \& Dragiewicz, M. (2019). Technologyfacilitated domestic and family violence: Women's experiences. British Journal of Criminology, 59, 551-570.

Dragiewicz, M., Burgess, J., Matamoros-Fernández, A., Salter, M., Suzor, N. P., Woodlock, D., \& Harris, B. (2018). Technology facilitated coercive control: Domestic violence and the competing roles of digital media platforms. Feminist Media Studies, 18(4), 609-625.

Enarson, E. (1999). Violence against women in disasters: A study of domestic violence programs in the United States and Canada. Violence Against Women, 5, 742-768.

Eneas, B. (2020). Advocate says Sask. women's shelters need more funding during COVID-19. CBC News. Retrieved May 19, 2020 from https://www.cbc.ca/news/canada/saskatchewan/ministrysocial-services-support-shelters-1.5518125.

Fairbairn, J., \& Dawson, M. (2013). Canadian news coverage of intimate partner homicide: Analyzing changes over time. Feminist Criminology, 8(3), 147-176.

Foster, H., \& Fletcher, A. (2020). Women's safety NSW update: Impacts on COVID-19 on domestic and family violence in NSW. Retrieved July 5, 2020 from https://www.womenssafetynsw.org. au/wp-content/uploads/2020/04/UDPATE_COVID19-Impac t-on-DFV-in-NSW_2.04.20_WSNSW.pdf.

Fried, I. (2020). Exclusive: Snapchat to offer in-app domestic violence support. Axios. Retrieved May 20, 2020 from https://www. axios.com/exclusive-snapchat-to-offer-in-app-domestic-viole nce-support-844cf1a9-60e0-425a-90ed-67e2e1f311ea.html.

Fulara, S. (2020). Developing a web-based platform to support domestic violence survivors. Brandeis Now. Retrieved May 18, 2020 from https://www.brandeis.edu/now/2020/may/dinna r-competition.html.

George, A., \& Harris, B. (2014). Landscapes of violence: Women surviving family violence in regional and rural Victoria. Deakin University. Retrieved May 6, 2020 from https://www.deakin.edu. au/data/assets/pdf_file/0003/287040/Landscapes-of-Violenceonline-pdfversion.pdf.

Gillespie, L. K., Richards, T. N., Givens, E. M., \& Smith, M. D. (2013). Framing deadly domestic violence: Why the media's spin matters in newspaper coverage of femicide. Violence Against Women, 19(2), 222-245.

Gold, J. (2020). The Covid-19 crisis too few are talking about: Health care workers' mental health. STAT News. Retrieved May 20, 2020 from https://www.statnews.com/2020/04/03/the-covid -19-crisis-too-few-are-talking-about-health-care-workers-menta 1-health/.

Greenberg, A. (2019). Hacker Eva Galperin has a plan to eradicate stalkerware. Wired. Retrieved June 29, 2020 from https://www. wired.com/story/eva-galperin-stalkerware-kaspersky-antivirus/.

Grierson, J. (2020). Domestic abuse killings 'more than double' amid Covid-19 lockdown. The Guardian. Retrieved April 20, 2020 from https://www.theguardian.com/society/2020/apr/15/domes tic-abuse-killings-more-than-double-amid-covid-19-lockdown.

$\mathrm{Gu}, \mathrm{J}$. (2019). Panic! at the browser: A quick intro to quick exit buttons [Conference presentation]. Prompt Conference, Chicago, IL.

Gunraj, A., \& Howard, J. (2020). Why is the COVID-19 pandemic linked to more gender-based violence? Canadian Women. Retrieved April 20, 2020 from https://canadianwomen.org/blog/ covid-19-pandemic-gender-based-violence/.

Hamberger, L. K., Larsen, S. E., \& Lehrner, A. (2017). Coercive control in intimate partner violence. Aggression and Violent Behavior, 37, 1-11.

Home Office (2015). Controlling or coercive behaviour in an intimate or family relationship. Retrieved May 15, 2020 from https:// www.gov.uk/government/uploads/system/uploads/attachment _data/file/482528/Controlling_or_coercive_behaviour_-_statu tory_guidance.pdf.
Iyengar, R., \& Sabik, L. (2009). The dangerous shortage of domestic violence services. Health Affairs, 28(1). Retrieved May 11, 2020 from https://www.healthaffairs.org/doi/full/10.1377/hltha ff.28.6.w1052.

Jenkins, P., \& Phillips, B. (2008). Battered women, catastrophe, and the context of safety after Hurricane Katrina. NWSA Journal, 20(3), 49-68.

Lamoureux, M. (2020). Nova Scotia mass shooting started as a domestic assault: Reports. VICE News. Retrieved May 6, 2020 from https://www.vice.com/en_us/article/v749x3/nova-scoti a-mass-shooting-started-as-a-domestic-assault-reports.

Lauve-Moon, K., \& Ferreira, R. J. (2017). An exploratory investigation: Post-disaster predictors of intimate partner violence. Clinical Social Work Journal, 45(2), 124-135. https://doi. org/10.1007/s10615-015-0572-z.

Lippy, C., Jumarali, S. N., Nnawulezi, N. A., Williams, E. P., \& Burk, C. (2020). The impact of mandatory reporting laws on survivors of intimate partner violence: Intersectionality, help-seeking and the need for change. Journal of Family Violence, 35, 255-267.

Lipsky, L., \& Burk, C. (2009). Trauma stewardship: An everyday guide to caring for self while caring for others. San Francisco: Berrett-Koehler Publishers.

Lowe, S. R., Rhodes, J. E., \& Scoglio, A. A. J. (2012). Changes in marital and partner relationships in the aftermath of Hurricane Katrina: An analysis with low-income women. Psychology of Women Quarterly, 36, 286-300.

Lum, D. (1996). Social work practice and people of color (3rd ed.). Monterey, CA: Brooks/Cole.

McCombs, M. E., \& Shaw, D. L. (1972). The agenda setting function of the mass media. Public Opinion Quarterly, 36, 176-187.

Meyer, C. (2020). Can a new app help domestic violence survivors? The Daily Democrat. Retrieved May 11, 2020 from https://www. dailydemocrat.com/2020/04/28/can-a-new-app-help-domesticviolence-survivors/.

Mithani, J. (2020). What we know about crises and domestic violence-and what that could mean for COVID-19. FiveThirtyEight. Retrieved May 18, 2020 from https://fivethirtyeight .com/features/what-we-know-about-crises-and-domestic-viole nce-and-what-that-could-mean-for-covid-19/.

National Coalition Against Domestic Violence. (2020). Why do victims stay? Retrieved May 6, 2020 from https://ncadv.org/whydo-victims-stay.

National Network to End Domestic Violence. (2020). Digital services toolkit. Retrieved May 19, 2020 from https://www.techsafety.org/ digital-services-toolkit.

Partington, R. (2020). Unemployment in US and UK 'may be worse than in Great Depression.' The Guardian. Retrieved April 28 , 2020 from https://www.theguardian.com/world/2020/apr/03/ coronavirus-uk-business-Activity-plunges-to-lowest-ebb-since -records-began.

PenzeyMoog, E. (2020). The framework for inclusive safety. Retrieved May 20, 2020 from https://www.inclusivesafety.com/resources.

PenzeyMoog, E. \& Slakoff, D. C. (in press). As technology evolves, so does domestic violence: Modern-Day tech abuse and possible solutions. In J. Bailey, A. Flynn, \& N. Henry (Eds.), Technologyfacilitated violence \& abuse: International perspectives and experiences. Bingley, England: Emerald Publishing Group.

Pfitzner, N., Fitz-Gibbon, K., \& True, J. (2020). Responding to the 'shadow pandemic': Practitioner views on the nature of and responses to violence against women in Victoria, Australia during the COVID-19 restrictions. Victoria: Monash Gender and Family Violence Prevention Centre, Monash University.

Rankin, J. (2020). GTA domestic violence groups brace for 'perfect storm' as abused women stay home amid COVID-19. The Toronto Star. Retrieved April 20, 2020 from https://www.thestar.com/ 
news/gta/2020/03/24/gta-domestic-violence-groups-brace-forperfect-storm-as-abused-women-stay-home-amid-covid-19.html.

Rao, S. (2020). A natural disaster and intimate partner violence: Evidence over time. Social Science and Medicine, 247. https://doi. org/10.1016/j.socscimed.2020.112804.

Rape, Abuse \& Incest National Network. (2020). Victim or survivor? Retrieved May 1, 2020 from https://www.rainn.org/articles/keyterms-andphrases.

Rawsthorne, S. (2020). Triple the threat: Coronavirus, family violence and child sex abuse. The Sydney Morning Herald. Retrieved April 20, 2020 from https://www.smh.com.au/national/nsw/triple-thethreat-coronavirus-family-violence-and-child-sex-abuse-20200 320-p54cd7.html.

Refuge. (2020). COVID-19/Coronavirus: Safety tips for survivors. Retrieved May 11, 2020 from https://www.refuge.org.uk/covid 19-survivor-tips/.

Richards, T. N., Gillespie, L. K., \& Smith, M. D. (2011). Exploring news coverage of femicide: Does reporting the news add insult to injury? Feminist Criminology, 6, 178-202.

Rossiter, K. R., Yercich, S., Baobaid, M., Al Jamal, A., David, R., Fairbairn, J., ... Jaffe, P. (2018). Domestic homicide in immigrant and refugee populations: Culturally informed risk and safety strategies. London: Canadian Domestic Homicide Prevention Initiative.

Ryan, C., Anastario, M., \& DaChunha, A. (2006). Changing coverage of domestic violence murders: A longitudinal experiment in participatory communication. Journal of Interpersonal Violence, 21(2), 209-228.

Safe \& Together Institute. (2020). Domestic violence-informed practice observations and tips from the front line of the pandemic. Retrieved from https://safeandtogetherinstitute.com/wp-content/ uploads/2020/05/MARAPR20-Virtual-Support-Group-Summary_ DS042220-1.pdf.

Sagesse. (2020). Domestic violence community protocols. Retrieved June 17, 2020 from https://www.sagesse.org/wp-content/uploa ds/2020/03/Domestic-Violence-Community-Protocol-COVID.pdf.

Selvaratnam, T. (2020). Where can domestic violence victims turn during Covid-19? The New York Times. Retrieved April 20, 2020 from https://www.nytimes.com/2020/03/23/opinion/covid-domes tic-violence.html.

Sety, M. (2012). Domestic violence and natural disasters. Retrieved May 1, 2020 from http://www.adfvc.unsw.edu.au.

Special Taskforce on Domestic and Family Violence. (2015). Not now, not ever: Putting an end to domestic and family violence in Queensland. Retrieved May 11, 2020 from https://www.qld.gov. $\mathrm{au} /$ community/documents/getting-support-health-social-issue/ dfv-report-vol-one.pdf.

Stark, E. (2007). Coercive control: How men entrap women in personal life. Oxford, England: Oxford University Press.

Surette, R. (2007). Media, crime, and criminal justice: Images, realities and policies (3rd ed.). Paris: Thomson.

Suzor, N., Dragiewicz, M., Harris, B., Gillett, R., Burgess, J., \& Van Geelen, T. (2019). Human rights by design: The responsibilities of social media platforms to address gender-based violence online. Policy \& Internet, 11(1), 84-103.
Taub, A. (2020). A new Covid-19 crisis: Domestic abuse rises worldwide. The New York Times. Retrieved April 20, 2020 from https:// www.nytimes.com/2020/04/06/world/coronavirus-domestic-viole nce.html.

Terrazas-Carrillo, E. C., McWhirter, P. T., \& Martel, K. M. (2016). Depression among Mexican women: The impact of nonviolent coercive control, intimate partner violence and employment status. Journal of Family Violence, 31, 721-734.

The Canadian Press. (2020). B.C. human rights observers concerned by spike in family violence amid COVID-19. The Toronto Star. Retrieved April 20, 2020 from https://www.thestar.com/news/ canada/2020/04/17/bc-human-rights-observers-concerned-byspike-in-family-violence-amid-covid-19.html.

The Learning Network at the Centre for Research \& Education on Violence Against Women \& Children in Canada. (2020). Intimate partner violence in a pandemic: COVID-19 related controlling behaviours. Retrieved May 29, 2020 from http://www.vawlearnin gnetwork.ca/our-work/infographics/LN-COVID-19-Related-Contr olling-Behaviours-PDF-2.pdf.

Thompson, A. (2020). Nation's largest hotel chain shelters domestic abuse survivors. The Sydney Morning Herald. Retrieved April 20, 2020 from https://www.smh.com.au/national/nsw/nation-s-large st-hotel-chain-shelters-domestic-abuse-survivors-20200406-p54hl 5.html.

Townsend, M. (2020). Revealed: Surge in domestic violence during Covid-19 crisis. The Guardian. Retrieved April 20, 2020 from https://www.theguardian.com/society/2020/apr/12/domestic-viole nce-surges-seven-hundred-per-cent-uk-coronavirus.

Unger, D. C. (2018). US news media under pressure: Then and now. SAIS Review of International Affairs, 38(2), 5-14.

VAWNet. (2020a). Keeping your cup full is essential to trauma informed advocacy part II (webinar). Retrieved May 19, 2020 from https:// vawnet.org/events/keeping-your-cup-full-essential-trauma-infor med-advocacy-part-ii.

VAWNet. (2020b). Resources for service providers. Retrieved May 19, 2020 from https://vawnet.org/sc/safety-privacy-digital-world /resources-service-providers.

Women's Refuge. (2016). The shielded site project. Retrieved May 11, 2020 from https://shielded.co.nz/.

World Health Organization. (2012). Intimate partner violence. Retrieved May 1, 2020 from https://apps.who.int/iris/bitstream/handle/10665 177432/WHO_RHR_12.36_eng.pdf.

World Health Organization. (2020). COVID-19 and violence against women. What the health sector/system can do. Retrieved May 4, 2020 from https://apps.who.int/iris/bitstream/handle/10665/33169 9/WHO-SRH-20.04-eng.pdf.

Yanovitzky, I. (2002). Effects of news coverage on policy attention and actions: A closer look into the media-policy connection. Communication Research, 29(4), 422-451.

Publisher's Note Springer Nature remains neutral with regard to jurisdictional claims in published maps and institutional affiliations. 